\title{
Las colecciones costumbristas en la segunda mitad del siglo XIX: Los españoles de ogaño
}

\author{
M. a ANGeles Ayala ARACil \\ Universidad de Alicante
}

En 1872 se publica una colección costumbrista, Los españoles de ogaño ${ }^{1}$, que intenta seguir las huellas de Los españoles pintados por sí mismos ${ }^{2}$. Esta colección aparece editada en dos volúmenes y al frente de cada uno de ellos encontramos prólogos que presentan y ofrecen de forma concisa y lacónica los rasgos peculiares de la obra. En el primero de ellos Victorino Suárez, editor de la colección, expone el propósito de la obra:

...Los autores de LOS ESPAÑOLES DE OGAÑO no han hecho otra cosa que escribir una segunda parte de Los españoles pintados por sí mismos ${ }^{3}$.

1 Las españoles de ogaño, colección de tipos de costumbres dibujados a pluma por los seftores..., Madrid, Librería de Victoriano Suárez, 1872, 2 vols., 8. ${ }^{\circ}, 395$ y 391 pp., respectivamente.

2 Las españoles pintados por si mismos, Madrid, Boix, 1843-1844, 2 vols., 4. ${ }^{\circ}, 4$ h., 446; $1 \mathrm{~h} .=2 \mathrm{~h} ., 505$ pp.., 1 h. grabs. y 100 láminas. La reproducción de Gaspar Roig, Madrid, $1851,4 .^{\circ}, 382$ pp., 1 h., 100 grabs., se publicó a cuatro pesetas. Luego el editor encuadernó ejemplares junto con las Escenas Matritenses de Mesonero Romanos.

3 Prólogo, tomo I, p. VI. 
V. Suárez enuncia los rasgos definidores de la colección al afirmar que los colaboradores describen sus tipos con gracia, ligereza e intención. La referencia a los dos primeros rasgos resume el postulado de El Curioso Parlante, postulado que podríamos sintetizar en la frase satira qua ridendo corrigit mores. El tercer punto, describir los tipos con intención, está más cerca de Larra, como si los jóvenes periodistas que figuran al frente de la colección ${ }^{4}$ se sintieran más identificados con el mordaz y peculiar estilo de Fígaro. Ambos escritores se proyectan, insistentemente, en los colaboradores de Los españoles de ogaño, al igual que ocurriera en la colección de 1843.

Como ya hemos señalado, Los españoles de ogaño aparece publicado en dos volúmenes, presentando un total de ochenta y seis tipos - cuarenta y cinco en el primer tomo y cuarenta y uno en el segundo-. Esta colección se aparta del resto de las colecciones costumbristas al aparecer sin ilustraciones, rasgo cuidado tanto en las colecciones francesas e inglesas como en las nacionales ${ }^{5}$.

4 Damos a continuación el índice de colaboradores por orden alfabético: Alcalde Valladares, Antonio; Barrera, Pedro M. ${ }^{2}$; Bedmar, Enrique G.; Bustillo, Eduardo; Campo Arana; Corrales y Sánchez, Enrique; Cortázar, E. de; Cortina, Francisco de la; Coupigny, Juan de; Esteban Collantes, Saturnino; Fernández Ruano, Manuel; Ferrán, Augusto; Flores, Eugenio Antonio; Frígola, Carlos; Frontaura, Carlos; Fuente Andrés, José de la; Garay de Sartí, José; Gil, Constantino; Jaques, Federico de; Luceño y Becerra, Alvaro; Luceño y Becerra, Tomás; Lustonó, Eduardo de; Matoses, Manuel; Mondéjar y Mendoza, Angel; Monreal, Julio; Moreno Godino, F.; Moreno López, Carlos; Ortí, Vicente; Palacio, Eduardo de; Palacios, Benjamín M. ${ }^{a}$; Pérez Echavarría, Francisco; Pérez Galdós, Benito; Pina Domínguez, M.; Príncipe, Enrique; Prugent, Enrique; Puig Pérez, José; Ramos Carrión, M.; Ruigómez e Ibarbia, Andrés; Sánchez Pérez, A.; Sanmartín y Aguirre, José F.; Santa Ana, Luis de; Santisteban y Mary, Rafael; Sepúlveda, Ricardo; Soriano de Castro, José; Uján; Valcárcel, Manuel; Zamora y Caballero; Rudheriq Al-Magheritit, S. C. A. y S. B. según los catálogos consultados corresponden a Eduardo de Mariategui, Salvador Constanzo y Salvador Bonavía, respectivamente.

5 Recordemos los primeros ejemplos importantes que iniciaron la idea de coleccionar artículos de «tipos» con exclusividad: Heads of the People y Les Français peints par eux-mêmes. En ambas colecciones las ilustraciones constituyen parte importante del texto. en The People los grabados, en madera, representan el busto o cabeza del tipo, corriendo a cargo del artista Kenny Meadows. Además de este grabado cada artículo lleva tres viñetas alusivas. En Les Français las ilustraciones corren por cuenta de los más ilustres artistas franceses del momento, como Gavarni, Daumier, Grandville, Johannot, Meissonier..., entre otros. Como en la obra 
Los tipos que aparecen en nuestra colección no obedecen a ninguna clasificación sistemática u orden prefijado con anterioridad. En la Presentación, segundo tomo, A. Sánchez Pérez reconoce la falta de unidad que se observa en la colección; de ahí que al prever las posibles críticas, justifique esa falta de unidad afirmando que «tal vez halles tipos análogos y aun idénticos, en dos artículos distintos; echarás de menos, en cambio, tipos que conocemos todos, pero tales defectos de conjunto, consecuencias inevitables de la precipitación y de la falta de acuerdo en obras de esta índole, están compensados con creces por los rasgos de ingenio, las pruebas de aguda observación y de perspicacia que aisladamente dan realce y prestan brillo a la obra» ${ }^{6}$.

Coincide con la mayoría de las colecciones costumbristas al presentar tipos de ámbito urbano, circunscritos a la ciudad de Madrid. Este hecho parece estar en contradicción con la declaración de intenciones que se nos ofrece en el Prólogo del primer tomo, en el que el propio editor, Victorino Suárez, señala que en Los españoles de ogaño «encontrarán dibujados con un esprit y una exactitud admirable, los infinitos tipos que en este último tercio del siglo XIX pululan por España» ${ }^{7}$. Sin embargo, los tipos aquí estudiados pertenecen a la sociedad madrileña de la época. En ciertas ocasiones el autor indica el origen provinciano de • alguno de ellos ${ }^{8}$ sin llegar a especificar su punto de origen. En

inglesa cada artículo va precedido de un grabado a toda página y un número de viñetas que oscilan entre dos y diez.

Las colecciones españolas también aparecen ilustradas, destacando sin duda la primera edición de Los españoles pintados por sí mismos, donde colaboran los artistas más prestigiosos de la época. La segunda edición presenta unas ilustraciones de menor calidad artística. Las colecciones derivadas de Los españoles ofrecen, con la excepción de Los españoles de ogaño, ilustraciones de mayor o menor calidad. En este sentido debemos hacer mención de la indudable calidad de las ilustraciones que acompañan a los artículos de Las mujeres españolas, portuguesas y americanas, ilustraciones que van cromolitografiadas en cartulina, en impresión independiente del libro, montadas fuera de texto sobre otra cartulina de color especial, en la que van enmarcadas en filete de oro y con rótulo al pie, también dorado.

6 Presentación, tomo II, p. III.

7 Prólogo, tomo I, p. V.

8 Vid. por ejemplo, el artículo La planchadora, de Julio Monreal. 
otros artículos se nos comunica la ascendencia andaluza o gallega del tipo ${ }^{9}$; e incluso, encontramos artículos donde la localización geográfica es más restringida: la Alcarria, lugar de nacimiento del tipo dibujado en La niñera. A pesar de estas localizaciones geográficas, los tipos regionales aparecen adaptados al nuevo ambiente y son retratados tal como desarrollan su actividad en la capital, por lo que son poco significativos respecto a su lugar de origen. Facilitar cualquier tipo de dato regional o folklórico parece estar muy alejado del propósito de esta colección. La única excepción que hallamos en este sentido es el artículo El catalán que muestra mediante la técnica perspectivística los caracteres diferenciados de dos catalanes, distintos entre sí en su manera de enfocar la vida y la política, y diferentes a su vez de la idiosincrasia del madrileño. Sólo dos artículos presentan al tipo ubicado fuera de Madrid: El señorito de pueblo y El secretario de ayuntamiento y ninguno de los dos ofrece información sobre la vida rural o provinciana.

Si intentamos hacer una escueta clasificación, totalmente arbitraria y por tanto con la única pretensión de analizar la realidad española que esta colección ofrece, observamos que los tipos y oficios que se nos muestran representan, en su gran mayoría, a la clase media urbana en sus distintos niveles. En el superior encontramos un grupo de artículos que dibujan la vida burguesa ${ }^{10}$, apareciendo el tópico del «quiero y no puedo» que más tarde se desarrollará magistralmente en los relatos de Galdós ${ }^{11}$. El parasitismo estatal viene representado únicamente por cinco tipos, número que contrasta con el ofrecido en Los españoles pintados por sí mismos. Margarita Ucelay $\mathrm{Da}$ Cal ofrece más de veinte

9 Vid. por ejemplo, El cantador, El matón o El cochero de alquiler, de Augusto Ferrán, Andrés Ruigómez y Eduardo de Palacio, respectivamente.

10 El catalán, El torero de afición, El del comercio, El banquero, El jugador de bolsa, Los pensionistas, El cómico de afición, El caballo blanco, La enamorada de un poeta, El solterón, El señorito de pueblo, El viejo verde, etc.

11 Merecen destacarse en este sentido artículos como El coleccionista, El hombre importante, El hombre necesario, El inglés... 
tipos que están directa o indirectamente relacionados con la vida y la organización oficial del Estado, pertenecientes a tres de sus sectores principales: el político, el ádministrativo y el eclesiástico ${ }^{12}$. En Los españoles de ogaño cuatro de estos cinco tipos pertenecen al cuerpo burocrático estatal ${ }^{13}$ y sólo uno representa al político ${ }^{14}$. El estamento eclesiástico, que en Los españoles pintados por sí mismos recoge más de siete tipos, brilla por su ausencia en nuestra colección. El estamento más representativo es el de las clases populares, siendo el grupo más numeroso el de los pequeños oficios, representados por un total de más de veinte tipos ${ }^{15}$.

Al comparar los tipos que se presentan respectivamente en Los españoles de ogaño y en la primera colección costumbrista española, se observa cómo los tipos eminentemente románticos, como por ejemplo el forajido, han sido sustituidos por un grupo bastante numeroso de tipos que pertenecen a los bajos fondos de la ciudad. Entre todos estos tipos se pueden establecer unas diferencias o matices. Un primer grupo va a responder a unas características más bien picarescas ${ }^{16}$. Son tipos que más que representar un oficio reflejan una forma de vida que les permite vivir sin trabajar, viven rayando en la delincuencia, a la cual indefectiblemente se encaminan. Su forma habitual de sobrevivir es engañar, y cada uno de ellos nos va a mostrar una variedad distinta de este único propósito. El segundo grupo se asemeja en mayor medida

12 Vid. M. Ucelay Da Cal, Los españoles pintados por sí mismos (1843-1844), México, 1951, p. 124.

13 El telegrafista, El cesante, El empleado y El empleado crónico.

14 El aspirante a ministro.

15 El sepulturero, La modista, El sastre, El memorialista, El pelero, La planchadora, El cochero de alquiler, El peluquero, El vendedor de periódicos, El mozo de café, El tabernero, El casero, La peinadora, El vendedor ambulante, La niñera, El trapero, El cantador...

16 El gancho, El petardista, El p̈obre vergonzante, La parroquiana de café, La mamá de teatro, El gorrista y El caballero de industria. 
al delincuente urbano, ya que su norma habitual de conducta es transgredir la ley ${ }^{17}$.

El resto de los tipos se reparten en distintos ámbitos, tales como la enseñanza ${ }^{18}$, laś artes ${ }^{19}$, la vida económica y las profesiones liberales. En lo que respecta a la vida económica se observa una mayor actividad y desarrollo económico al presentarnos tipos como El banquero y El jugador de bolsa. Las profesiones liberales están representadas únicamente por dos tipos, El homeópata y un tipo que se había echado en falta en Los españoles pintados por si mismos: El abogado ${ }^{20}$.

Además de la ausencia de representantes del clero hay que subrayar la omisión, al igual que en la colección de 1843 , de jerarquías militares. La nobleza tampoco se constituye en tipo y las escasas referencias que se encuentran indican cómo los burgueses intentan imitar el género de vida aristocrático ${ }^{21}$. De esta forma se observa que los estamentos poderosos del antiguo régimen -nobleza, clero y ejército- quedan fuera del área de exploración de nuestros costumbristas, lo que parece poner de manifiesto el respeto y temor que en 1872 todavía inspiraban.

El guripa, El vendedor de periódicos y El matón.

El maestro de escuela, El estudiante de medicina, El maestro de lenguas, Los pensionistas...

19 El zarzuelero, La suripanta, El bohemio, El pianista, El bailarín, El cómico casero, El cómico de afición, El crítico, El poetastro, La literata...

20 Es bastante peculiar que se incluyera por primera vez el tipo «el abogado» en Los españoles de ogaño, ya que el siglo XIX, que representa escaso desarrollo industrial, científico y técnico, es, en cambio, la época de grandes transformaciones juridicas, de exuberante legislación y codificaciones. Consecuente con esta realidad, no debe extrañar que la gran mayoria de la población estudiantil se decante por la carrera de Derecho. Manuel Tứón de Lara en La España del siglo XIX, Barcelona, Ed. Laia, 1973, p. 174, ofrece unos datos muy apreciables del curso 1859-1860. De un total de unos seis mil estudiantes, casi cuatro mil cursaban sus estudios en la Facultad de Derecho; ciento cuarenta y uno cursaban èn las Facultades de Ciencias; treinta y ocho en la Escuela de Arquitectura; veintisiete en la de Ingenieros Agrónomos y cuatrocientos ochenta y nueva en la de Industriales. Teniendo en cuenta estos datos, parece imprescindible la presencia de «el abogado» en una colección de este signo.

21 Vid. artículos como El pianista, El cómico de afición, El hombre necesario, El sastre, El revistero, etc. 
Por último, encontramos un gran número de tipos que, bien por su índole general o bien por representar determinadas características psicológicas, son difíciles de situar en un estamento concreto. Entre ellos cabría destacar artículos como Aquél, El tipo universal, Mi amigo íntimo, La cursi, El cominero...

$\mathrm{Si}$ respecto a la inclusión de tipos existen apreciables diferencias debidas, sin duda, al cambio operado en la sociedad española y a los distintos movimientos literarios en que se producen estas dos manifestaciones costumbristas, no ocurre lo mismo respecto a las técnicas utilizadas. Los procedimientos empleados por los colaboradores de Los españoles de ogaño no suponen ninguna innovación sustancial en el género. El contenido, enfoque y formas de locución nos recuerdan los recursos utilizados por los costumbristas románticos, modificándose ligeramente algunos aspectos, como veremos más tarde. Los artículos, prácticamente en su totalidad, aparecen escritos en prosa, aunque encontramos algunos elaborados en verso - La cursi, El gorrista y La peinadora-y otros donde se combinan ambas modalidades -El hombre necesario y El tabernero- ${ }^{22}$.

En nuestra colección la escena, cuando la acción se suprime y se concede al ambiente el rango de protagonista, no existe. El propósito del escritor es reflejar exclusivamente el tipo y sólo en función de él podemos encontrar algunos bocetos que nos recuerden la escena costumbrista, como sucede, por ejemplo, en $E l$ tabernero, donde su autor, en un intento de perpetuar la tradición y el pintoresquismo andaluces, se recrea en describir sin ningún género de premura las características tradicionales de una taberna andaluza, enfrentándola a las novedades impuestas por las

22 La utilización de verso no tiene nada de extraño, ya que fue admitido por los cultivadores del género desde el siglo XVIII y aparece con relativa frecuencia en las colecciones costumbristas decimonónicas que toman como ejemplo la primera colección española - Los españoles pintados por sí mismos - en la que se presenta cuadros escritos en verso - El cartero y El calesero- y cuadros que lo intercalan con la prosa - La nodriza, La gitana y La maja-. La prensa también se hace eco de esta modalidad y sería interminable la lista de cuadros escritos en verso aparecidos en periódicos como El Semanario Pintoresco Español, El Laberinto, El Museo de las Familias, etc. 
modas de nuevo cuño que imperan en las botillerías o tabernas del Madrid de la época.

Los títulos que encabezan y presentan el contenido de los diferentes artículos hacen referencia al nombre del tipo protagonista del artículo, a excepción de Aquél, de Benito Pérez Galdós, cuyo título no aporta información alguna sobre la naturaleza del tipo o escena pintada ${ }^{23}$.

Los lemas - tan frecuentes a partir del siglo XVIII y en boga durante el Romanticismo- son escasos en nuestra colección. De un total de ochenta y seis artículos sólo encontramos diecisiete de ellos que los utilicen ${ }^{24}$, lo que parece indicar que su uso no es en estas fechas tan abusivo como denunciara Larra en su artículo Manía de citas y epígrafes. Se utilizan citas de autores clásicos o ya consagrados, como Cervantes, Iriarte, Shakespeare, H. de Balzac, Martínez de la Rosa... Otros, están escogidos con sigular subjetivismo y, por lo tanto, lo único destacable en ellos es su mayor o menor gracia, o su adecuación al tema del artículo. Entre ellos podríamos destacar el protagonizado por El filósofo moderno, de Enrique Prugent, que tan gráficamente adelanta las conclusiones de su artículo:

$$
\begin{aligned}
& (i \ldots ! \ldots i \ldots ? \ldots) \\
& \text { NADIE }^{25} .
\end{aligned}
$$

23 Correa Calderón en Costumbristas españoles..., Madrid, Aguilar, 1951, Cap. «Análisis del cuadro costumbrista», pp. LXXI-LXXVI, señala que existen varias modalidades de títulos, destacando el uso frecuente de títulos dobles, unidos por la conjunción $o$ que posee valor aclarativo, de identidad, así como títulos compuestos por dos conceptos u objetos antagónicos unidos por la conjunción $y$. Por último, incluye títulos compuestos por largas frases que resumen el contenido del artículo. Sin embargo, en nuestra colección no aparece ninguna de estas modalidades.

El bohemio, La niñera, La modista, El filósofo moderno, El agente fúnebre, El noticiero, El casero, El farol, El sepulturero, El matón, Los pensionistas, La planchadora, El zarzuelero, La mamá de teatro, El inventor, El homeópata y El sepulturero. 
Los escritores suelen empezar el artículo o bien mediante la captación de benevolencia, como por ejemplo se aprecia en $L a$ suripanta, El bohemio, El torero de afición, La literata..., o mediante la digresión -El zarzuelero, El vendedor de periódicos, El fotógrafo, El pianista...-; e incluso, utilizando estos dos procedimientos al unísono, como sucede en El tabernero y El abogado. Mediante la citada captación de benevolencia el autor intentará mostrarse abrumado ante la importancia del tipo encomendado, exponiendo las dificultades que ello le ocasiona e intentando ganarse las simpatías del presunto lector. En muchos casos el comienzo del artículo va precedido de fórmulas similares a éstas:

Peliagudo es el retrato y dígoles a Vds. que no sé qué parecido va a sacar.

¿Si fuera en otros tiempos!

Pero ahora apenas voy por el reino bufo, que apenas conozco más que a su rey Arderius, francamente, no sé que hacer de provecho para cumplir mi delicada misión ${ }^{26}$.

Nada puede encontrarse tan difícil en la actualidad, como colocar bajo la magia del pincel este alegre personaje, oscuro y sombrío en otros tiempos, como decididor, contento y vivaracho en los presentes. Por eso creemos que es una empresa sobradamente arriesgada y quizás superior a unas fuerzas flacas como las nuestras, intentar la descripción de un ser cuya naturaleza ha variado y cuyo carácter ha tomado otro rumbo ${ }^{27}$.

Las digresiones eruditas son muy utilizas por el costumbrismo, acercándose en este sentido a la técnica de la novela histórica y a la del folletín ${ }^{28}$. En estas tres modalidades literarias el autor intentará poner de manifiesto la profundidad de sus conocimientos con el firme propósito de hacer valer sus méritos. Sin embar-

26 La suripanta, tomo I, p. 24.

27 El tabernero, tomo II, p. 22.

28 Vid. el artículo de Enrique Rubio, «Novela histórica y folletín», Anales de Literatura Española, Universidad de Alicante, núm. 1, 1982, pp. 269-281, en el que el autor analiza los recursos comunes a ambos géneros narrativos y que coinciden además con aspectos del costumbrismo. 
go, hay que subrayar que en el costumbrismo, por la brevedad del texto, la digresión erudita suele ser de menor extensión y, a veces, de un academicismo un tanto dudoso, ya que se pueden encontrar digresiones pseudo-eruditas e incluso humorísticas, como son las que narran los orígenes del tipo desde una perspectiva cómico-histórica ${ }^{29}$. En ocasiones las digresiones se utilizan con la finalidad de crear un ambiente propicio que arrope la descripción del tipo, que sin ese abanico informativo podría quedar desdibujado en algunos casos.

Si sostenemos que el escritor de costumbres, como afirma Juan Ignacio Ferreras, "suele partir de una moral, de una política, de una ideología en suma, que al no ser debatida en la obra, atraviesa incólume la misma» ${ }^{30}$, la digresión se nos presenta como botón de muestra de la ideología, visión del mundo u opinión que el escritor tiene de la realidad que lo rodea, utilizándola para poner de manifiesto sus aseveraciones sobre un tema, del que va a extraer el tipo como ejemplarización que corrobore sus especulaciones. Un claro ejemplo de lo que acabamos de afirmar lo encontramos en El vendedor de periódicos, en el que Ricardo Sepúlveda muestra su pesimismo sobre el progreso político que se sigue en España ${ }^{3 !}$.

La descripción de los rasgos físicos del tipo y su vestimenta es ofrecida posteriormente. Esta descripción se elabora a base de pinceladas, en una perfecta adecuación, en la mayoría de los casos, entre los rasgos físicos y los psíquicos del tipo. La descripción exterior no es demasiado abundante en esta colección, dibu-

Los ejemplos son innumerables. Destacamos entre otros: El zarzuelero, El vendedor de periódicos, El fotógrafo, El pianista, El guripa, El caballero de industria, El sietemesino, El tabernero, El abogado, El cochero de alquiler, El sepulturero, etc.

30 Juan Ignacio Ferreras, «La prosa en el siglo XIX», Historia de la Literatura Española, Madrid, Guadiana, 1974, vol. III, p. 81.

31 Además de este articulo la colección presenta numerosas muestras. Vid., por ejemplo, El zarzuelero, El Casero, El telegrafista, El petardista, El noticiero, El agente fúnebre, La mamá de teatro, La parroquiana de café, El empleado, El torero de afición, El... del comercio, El caballero de industria, La modista... 
jándose, por norma general, las características esenciales del tipo y su modo de hacer, sin ofrecer datos concretos en cuanto a su forma de vestir ${ }^{32}$. En esto difiere de otras colecciones - caso de Los valencianos pintados por sí mismos ${ }^{33}$ o Las mujeres españolas, portuguesas y americanas - ${ }^{34}$ en las que por la ubicación geográfica de sus tipos y por su claro matiz folklórico aparecen descritos multitud de trajes típicos de las distintas regiones españolas e hispanoamericanas.

En Los españoles de ogaño la descripción física se intensifica cuando el tipo realiza un oficio popular u ofrece connotaciones provincianas, sobre todo si proviene de alguna región andaluza. Un ejemplo significativo en este sentido es el ofrecido por Augusto Ferrán en El cantador, donde se describe de forma minuciosa el aspecto físico y la vestimenta del tipo:

Hace pocos días llegó a Madrid con las pretensiones que luego se indicarán. No es alto ni bajo; su cara es vulgar, frente mediana que estrecha el cabello negro peinado sobre las sienes hacia adelante, ojos pardos y vivos, boca algo ancha, de labios gruesos y rectos casi; aspecto un tanto orgulloso, andar un mucho arrogante; viste sombrero hongo, chaqueta corta de felpa negra, camisa entre sucia y limpia, con sus imprescindibles gemelos y botones en el cuello y la pechera, faja oscura, pantalón claro y ceñido, y calza botitos de charol, siempre de charol ${ }^{35}$.

32 Entre los escasos ejemplos destacamos los siguientes: El estudiante de medicina, El caballero de industria, El tabernero, El mozo de café, El peluquero, El librero de viejo, El viejo verde y El cantador.

33 Los valencianos pintados por sí mismos. Obra de interés y lujo escrita por varios distinguidos escritores, Imprenta de la Regeneración Tipográfica, de don Ignacio Boix, Valencia, 1859. Existe una edición facsímil realizada en Valencia en 1978, por Artes Gráficas Soler.

34 Las mujeres españolas, portuguesas y americanas. Tales como son en el hogar doméstico, en los campos, en las ciudades, en el templo, en los espectáculos, en el taller y en los salones. Descripción y pintura del carácter, costumbres, trajes, usos, religiosidad, belleza, defectos, preocupaciones y excelencias de la mujer de cada una de las provincias de España, Portugal y Américas Españolas. Obra escrita por los primeros literatos de España, Portugal y América, e ilustrada por los más notables artistas españoles y portugueses, Madrid-La Habana-Buenos Aires, Imprenta y Librería de don Miguel Guijarro, 3 vols., 1872, 1873 y 1876.

El cantador, tomo II, p. 35. 
Si analizamos la forma de locución, procedimientos y recursos literarios que aparecen en nuestra colección, debemos señalar que la descripción directa se utiliza en numerosos artículos como único medio de expresión. El autor presenta al tipo tal y como él lo ve y lo siente, con una mayor o menor objetividad, siempre dependiendo de su voluntad y sabiduría ${ }^{36}$. Frente a estos artículos puramente descriptivos, el resto de los que aparecen en la colección utilizan el diálogo para provocar un mayor realismo.

Atendiendo al punto de vista que el autor emplea, también encontramos posturas diferentes. Por un lado, observamos escritores que adoptan la técnica decimonónica del autor omnisciente, es decir, simulan un conocimiento completo de los distintos personajes y acontecimientos que se suceden en el cuadro ${ }^{37}$. Por otro lado, el autor se nos presenta en continuo diálogo con el lector ${ }^{38}$, intentando captar de esta forma la atención del mismo. Estos artículos en nuestra colección suelen comenzar con una frase interrogativa del tipo siguiente:

No extrañen nuestros lectores que comencemos este artículo con una pregunta. ¿Saben Vds. lo que es necesario para ser un buen zarzuelero? ${ }^{39}$.

En ocasiones el autor se nos presenta como protagonista del cuadro, bien como testigo que observa y da fe de la realidad descrita, o bien como personaje que interviene en el desarrollo argu-

Vid., por ejemplo, La planchadora, El bohemio, El maestro de escuela, El periodista de oficio, El vendedor ambulante, El cantador, El empleado crónico, El vendedor de billetes, El peluquero, El cómico casero...

Esta postura se aprecia claramente tanto en los artículos que utilizan la descripción como única vía expresiva como en aquellos otros donde se introduce la ejemplificación del tipo.

Peculiaridad clásica entre los novelistas del siglo XIX. Tanto el folletín como la novela histórica y la novela realista-naturalista utilizarán este recurso literario. En nuestra colección se puede observar en artículos como El zarzuelero, El agente fúnebre, La niñera, El mozo de ca$f e$, etc. 
mental del cuadro. En El... del comercio, de Eugenio Antonio Flores, se nos ofrece una muestra de autor-protagonista que observa al tipo-objeto del cuadro. El artículo se inicia con las significativas palabras de «... Y a las dos de la mañana entraba yo en el café de la Iberia» ${ }^{40}$, y es allí donde encuentra al tipo. El autor es fiel transcriptor de los hechos sin escudriñar el estado anímico de aquél ${ }^{41}$.

Algunos autores prefieren salirse de los límites propios del género, prescindiendo de la descripción del tipo para entrar directamente en la acción propia del relato, como sucede en el artículo El orador de club. En estos artículos el autor finge un asunto e introduce unos personajes, creando con ello una peripecia argumental que lo aproximará al cuento ${ }^{42}$. La incorporación del cuento al cuadro de costumbres no es nueva. Artículos de Larra como En este país, Vuelva usted mañana, Yo quiero ser cómico o El castellano viejo son claros ejemplos de este tipo de artículos con acción, personajes y diálogos que guardan estrecha relación con el cuento. Incluso la misma intención poética o complicación de la peripecia argumental - como diría Baquero- aumenta esta semajanza. El artículo De tejas arriba, de Mesonero Romanos, ofrece una narración compuesta por cinco capítulos -Madre Claudia, Las buhardillas, Drama de vecindad, Peripecia y Desenlace- que por su extensión, presencia de personajes, movimiento y movilidad del relato son más propios de un cuento que de un cuadro costumbrista. De igual forma el artículo El retrato se acerca por su contenido y argumento - trasiego ininterrumpido de escenario y dueño- al cuento que tiene como protagonista un objeto, como sucediera con el conocido relato de

40 El... del comercio, tomo I, p. 295.

41 En la colección encontramos varias muestras de autor asimilado a personaje secundario que narra en primera persona la historia del «tipo», historia que él conoce por estar envuelto de alguna manera en ella. Citaremos entre otros los artículos El amigo íntimo, El proyectista, El tabernero, El coleccionista...

42 Vid. M. Baquero Goyanes, El cuento español en el siglo XIX, Madrid, CSIC, 1949, p. 96. 
Alarcón $E l$ clavo $^{43}$. Es difícil precisar en ocasiones los límites del artículo de costumbres y el cuento, al presentar el primero una peripecia argumental que rebasa las fronteras del cuadro costumbrista, incidiendo y desembocando en el cuento; de ahí que muchas antologías de cuentos incluyan no pocos artículos de costumbres al lado de relatos definidos o rotulados bajo la etiqueta de cuentos, como el citado de Mesonero Romanos - El retratoo El castellano viejo, de Larra ${ }^{44}$.

En Los españoles de ogaño encontramos bastantes muestras de cuentos, aun reconociendo que son cuentos mediocres donde el afán costumbrista por retratar la realidad tal y como es oprime en demasía el argumento, desarrollo e independencia de relato. Destacan por su gracia o amenidad artículos como El torero de afición de Carlos Moreno López; El español independiente de Francisco Pérez Echevarría, cuento satírico sobre la clase política del momento; Los pensionistas de Sánchez Pérez, donde se pone en tela de juicio la moda y conveniencia de mandar a los jóvenes a internados españoles o franceses. En La niñera de C. Moreno López, se incluye una escena entre la niñera y un soldado, teniendo como telón de fondo la Puerta del Sol, llena de gracia y socarronería y, aunque su autor califica globalmente su artículo de cuadro y cuento indistintamente, esta última escena muy bien podría acomodarse en una antología de sainetes; La suripanta de Luis de Santa Ana; El señorito de pueblo... Por otro lado, cabe destacar que en algunos de estos cuentos se repiten de forma más o menos intencionada personajes que ya han aparecido con anterioridad en novelas o cuentos de corte realista, como sucede, por ejemplo, con el protagonista de El coleccionista -Cayo Paniucci-que se halla estrechamente vinculado con el petimetre -Villamelón- creado por el P. Coloma. Este cuento es el que

43 Ibid., Cap. XIII, «Cuentos de objetos y seres pequeños», pp. 489-521.

44 Federico Sainz de Robles en Cuentistas españoles del siglo $X I X$, incluye el artículo de Estébanez Calderón Pulpete y Balbeja; Pedro Bohigas en Los mejores cuentistas españoles, Madrid, Ed. Plus Ultra, 1946, tomo I, incluye el artículo anterior y los titulados El castellano viejo de Larra y Una noche en vela de Mesonero Romanos; Menéndez Pidal en su Antología de cuentos, Barcelona, Labor, 1935, inserta El castellano viejo de Larra. 
presenta una mayor complejidad en su estructura. El articulista actúa como narrador de una historia y como personaje real del artículo, mientras que el «tipo», una vez presentado por el narrador, se independiza de su voz y adquiere vida propia, desempeñando a su vez el papel de personaje del artículo en un primer momento y, posteriormente, el de protagonista del cuadro. Incluso, encontramos otros cuentos cuya intención, como en el caso de El solterón, se asemeja a la sostenida en El buey suelto de Pereda o a la ofrecida por A. Flores en su Historia del Matrimonio.

Uno de los procedimientos o recursos narrativos más interesantes y practicado por un gran número de costumbristas es el epistolar, que permite analizar comportamientos y usos desde una perspectiva nueva, creada por el autor para denunciar las costumbres que la misma sociedad protagoniza. El recurso no es nuevo, utilizándolo en el siglo XVIII Cadalso en sus Cartas Marruecas al fingir un intercambio de cartas entre Gazel - joven moro llegado a España en una embajada-, Ben-Beley - su preceptor-y Nuño, alter ego de Cadalso. El choque de perspectivas utilizado por Cadalso encaja perfectamente en la sátira costumbrista, al enfrentar dos modelos contrapuestos: lo usual y lo inusual, la cotidianeidad y la sorpresa. Como acertadamente indica el profesor Baquero Goyanes «el buen escritor costumbrista es aquel que enseña a mirar y a descubrir, el que es capaz de elevar a gracia literaria la menuda anécdota de cada día, la cotidiana trivialidad de los tipos y ambientes que nos rodean. Para conseguir esto, el articulista suele utilizar un efecto perspectivístico: el ofrecer lo por todos conocido bajo una luz nueva y reveladora» ${ }^{45}$. El escritor costumbrista debe tener la inteligencia o capacidad para percibir lo cotidiano y usual y para obtener nuevos enfoques de la cotidianeidad conocida. Es fácilmente comprensible que los costumbristas finjan sorpresa o asombro ante el conocimiento de ciertas conductas sociales que, lejos de beneficiar a la sociedad, actúan en su detrimento. Larra, en su artículo Vuelva

\footnotetext{
45 M. Baquero Goyanes, Perspectivismo y contraste, Madrid, Gredos, B.R.H., 1963, pp. 26-27.
} 
usted mañana, utiliza el choque de perspectivas para censurar la inoperancia y la lentitud de la burocracia. En este caso se enfrenta la actitud de un extranjero - monsieur Sans-délai- y el peculiar comportamiento de la sociedad y burocracia españolas.

En otros casos el costumbrista utiliza para sus propósitos a un interlocutor nacido y educado en España. El castellano viejo de Larra, por ejemplo, es el tipo representativo de una sociedad que no sólo alardea de estar en posesión de las buenas costumbres, sino que las lleva a límites tan extremos que producen en el escritor un efecto desolador. El choque de perspectivas enfrenta a nuestro castellano viejo - don Braulio- y a Fígaro, representantes de dos formas de entender los buenos usos. Si es natural el choque de perspectivas entre individuos pertenecientes a una misma clase social y a un idéntico núcleo urbano, no menos usual es el enfrentamiento de perspectivas entre un provinciano y un cortesano, como es el caso de Los paletos de Madrid de Mesonero Romanos.

Otra modalidad de este mismo recurso es la yuxtaposición de perspectivas opuestas ${ }^{46}$, como sucede en una de las Cartas desde las Batuecas del Bachiller Pérez de Munguía a Andrés Niporesas, en la que se plantea la siguiente interrogante: «¿No se lee en este país porque no se escribe, o no se escribr porque no se lee?». A renglón seguido Fígaro nos presenta dos perspectivas de la interrogante anteriormente citada.

La técnica perspectivística también se halla presente en Los españoles de ogaño, si no adaptándose completamente a los modelos enumerados y que tan magistralmente avalaron los grandes maestros del género, sí, al menos, en bastantes variaciones y ampliaciones de este recurso tan característico del costumbrismo. El único artículo que intenta aprovecharse de la experiencia acumulada por costumbristas anteriores es El catalán, de Francisco de la Cortina. El artículo es un intento fallido de conjugar un doble juego perspectivístico. Por un lado, contrastar la opinión del propio autor - madrileño- y de dos catalanes recién llegados a 
la capital; y por otro, presentar a dos individuos oriundos de la misma región y que representan a su vez dos perspectivas distintas del hecho catalán. El artículo apenas ocupa cuatro páginas, lo que es iňsuficiente para llevar a cabo la original y complicada idea de su autor. Se limita a ofrecernos una superficial valoración de la esencia madrileña para centrarse un poco más en las diferencias existentes entre estos dos tipos catalanes. Presenta a Federico Carbonell como hombre que ama a su tierra, actitud que en él es compatible con el convencimiento de que existen elementos positivos fuera de ella. Por el contrario, Andrés Riscat es un catalán convencido de que lo auténtico y positivo sólo se encuentra en Cataluña. Este personaje se considera catalán, no español, expresando el conflicto que estallará poco más tarde con extremada virulencia.

- Madrid, me respondió, a él he venido por necesitarlo mis intereses; de no ser así no hubiera salido de Barcelona, y con franqueza, como buen catalán, le digo a usted que no encuentro en Madrid nada que pueda ponerse enfrente de aquello.

- Sin embargo, repuse algo picado, aquí tenemos cosas que valen más indudablemente que aquello.

— ¿Qué dice V., caballero? ¡Si Barcelona!... ¡Si Cataluña!... ¡Oh! Cataluña...

-Déjale, me dijo Federico en voz baja, es un catalán cerrado al que no sacarás de sus creencias aunque te empeñes, que no te concederá en nada superioridad a Cataluña, y en fin, que si le preguntas que si es español te responderá que no, que es catalán ${ }^{47}$.

Entre los artículos que ofrecen una ampliación en el uso de la perspectiva, posiblemente sea El fotógrafo de Ramos Carrión el más significativo. El tipo apenas es descrito por el propio autor, sino que se nos va presentando indirectamente esbozado a través de los distintos personajes - soldado, joven, niña, pareja de enamorados...- que el autor hace desfilar por su estudio fotográfico, personajes que nunca quedarán satisfechos con el trabajo del

47 El catalán, tomo I, p. 229 . 
paciente fotógrafo, siendo precisamente esa paciencia el rasgo definidor del tipo ${ }^{48}$.

Al igual que Mesonero Romanos ${ }^{49}$, Antonio Flores ${ }^{50} \mathrm{o}$ Larra ${ }^{51}$, la mayoria de los colaboradores de Los españoles de ogaño designan a sus tipos con nombres y apellidos, como si trataran de esta forma de distanciarse de la rigidez de la pintura de tipos y dotarles así de un mayor realismo ${ }^{52}$. En algunos artículos los autores prefieren que sus tipos utilicen un nombre y apellido que esté en relación directa con la actitud o característica que sirve para definirles, como es el caso de don Fermín Carnero y Becerrete $^{53}$ - hombre dedicado a realizar las tareas domésticas mientras su mujer es la que resuelve los asuntos de la calle-, o don Cándido Cuenca ${ }^{54}$-hombre débil que se deja engañar fácilmente y arriesga todo su dinero en una empresa ruinosa-. En otros artículos encontramos personajes cuyos nombres presentan un claro matiz caricaturesco: Curro Piesdepluma ${ }^{55}$ es el nombre

48 Una perspectiva similar es of recida por Galdós en sus artículos La mujer del filósofo y Cuatro mujeres, publicados en la colección Las mujeres pintadas por los españoles, donde la mujer es analizada desde la óptica o profesión del marido y no por su propio comportamiento o actitud.

49 Este tipo de onomástica es frecuentísima entre los personajes dibujados por Mesonero Romanos, por ejemplo, D. Plácido Cascabelillo, D. Pascual Bailón, D. Solicito Ganzúa, Juan Cochura, D. Teodoro Sobrepuja, Patricio Mirabajo, D. Perpetuo Antañón, D. Horacio Buenafé, etc.

5) Antonio Flores en Ayer, hoy y mañana nos ofrece los siguientes: D. Ambrosio Tenacillas, D. Narciso Ceremonial, D. Restituto Igualdes, D. Silvestre Terror, La Cicerona, D. Cándido Retroceso, D. Plácido Regalías y Privilegios, etc.

51 Nos referimos a tipos como Cándido Buenafé o Andrés Niporesas.

\$2 Vid. entre otros los artículos El cominero, El torero de afición, El empleado, El noticiero, El coleccionista, El catalán, El bailarín. El cómico de afición, El proyectista, El caballo blanco, El señorito de pueblo, El periodista peatón, El farol, etc.

53 Protagonista de El cominero, tomo I, pp. 71-75.

s4 Vid. El caballo blanco, tomo II, pp. 336-344.

55 El bailarín, tomo I, pp. 232-236. 
que Eugenio Antonio Flores escoge para un pobre bailarín que muere sin conocer la gloria; Francisco Pérez Echevarría designa al individuo que constantemente está proyectando negocios y actividades, pero que nunca llegan a realizarse, como don Calisto Trajín y Polvorosa ${ }^{56}$; Juanito Bambalinas ${ }^{57}$ es el nombre que Eduardo Bustillo brinda al joven aficionado a representar comedias en reuniones sociales; a la diva de mal genio que no puede sufrir las críticas negativas por su mala actuación teatral, Andrés Ruigómez la bautiza con el nombre de Olimpia Mildemonios ${ }^{58}$; José F. Sanmartín y Aguille llama don Meteme-en todo y don Ridículo Farol ${ }^{59}$ a personajes que hablan de todo y no entienden de nada, etc. ${ }^{60}$.

En Los españoles de ogaño encontramos artículos que ofrecen cierta originalidad en la presentación del tipo correspondiente. Destacan en este sentido artículos donde se recurre a reproducir al principio del mismo cualquier papel administrativo, artículo de prensa, esquela mortuoria, etc. que enmarcan la descripción del tipo. Así, por ejemplo, en El cesante Ramos Carrión se sirve de la reproducción de un pliego de cese y nombramiento para abrir y cerrar respectivamente el artículo:

Receta para hacer un cesante. Tómese un pliego de papel, dóblese a medio margen, y escríbase sobre poco más o menos lo siguiente:

El director de tal ramo ha tenido a bien declarar a V. cesante en esta fecha, con el haber que por clasificación le corresponda.

57 Es el protagonista de El cómico de afición, tomo II, pp. 151-163. dad española, Madrid, Castalia, 1960, p. 65, afirma que la utilización de estos nombres significativos lo que hace es destacar el carácter caricaturesco y desarraigar a los tipos de toda realidad a fuerza de exageraciones innecesarias. 
Lo que comunico a $\mathrm{V}$. para su conocimiento y efectos consiguientes ${ }^{61}$.

De esta forma, con la fría e impersonal reproducción del cese, Ramos Carrión logra, desde el inicio del artículo, el clima de desolación que envuelve al individuo que lo recibe. Idéntico procedimiento emplea Eugenio A. Flores para presentar a su tipo en $E l$ bailarín. En este caso el motivo reproducido es una esquela mortuoria que llena completamente la primera página del artículo, acompañada con la reproducción de una necrológica aparecida en una supuesta Gacetilla, que recoge satíricamente los honores y triunfos profesionales que alcanzó en vida.

Por último queremos subrayar el artículo de Benito Pérez Galdós, artículo que sobresale sin lugar a dudas del resto de la colección. Su originalidad se manifiesta desde el principio en el título mismo del artículo - Aquél-, apartándose de esta manera de la norma general de rotularlos con el nombre de la profesión u oficio o con el nombre del escenario donde transcurre la trama del cuadro. Se inicia con la interrogante «¿Quién es aquél?», utilizada para provocar en el lector la duda o suspense, suspense que se prolongará hasta el final del cuadro, pues el lector llega a él sin averiguar a ciencia cierta de quién se está hablando. En la primera parte del artículo, Galdós, con suma maestría, ofrece un juego de interrogantes y respuestas sobre la identidad misteriosa del tipo. Por un lado muestra una lista de lugares donde lo podríamos encontrar para, a renglón seguido, ofrecer una serie de individuos que pueden responder al tipo - un marqués, un conde, un filósofo, un hombre de talento, un político...- manifestando con esa doble falta de concreción la universalidad del tipo. Veamos un párrafo cualquiera del artículo:

Como respondiendo que aquél no es nadie iríamos a parar a un absurdo, es fuerza convenir en que aquél es una persona que se encuen-

6i El cesante, tomo I, p. 216. La huella de Mesonero Romanos es patente. El personaje de ficción creado por El Curioso Parlante - D. Homobono Quiñones-incide directamente en el artículo. 
tra en todas partes, lo mismo en los espectáculos gratuitos que en los de pago, los mismo en los tristes, como en entierro, que en los alegres, como el baile; figura decorativa de los cafés y de los teatros; parte alícuota de todo numeroso y escogido público en las reuniones y meetings; un hombre que siempre estamos viendo y nunca conocemos, un tipo de los tipos, raras veces simpático; por lo común, insoportable, ente aborrecido, que nadie sabe cómo se llama, ni quién es, ni qué hace, ni de qué vive ${ }^{62}$.

En la segunda parte el autor sigue paso a paso, como si de una máquina fotográfica se tratara, el minucioso recorrido del personaje por calles, plazas y jardines de Madrid, entroncando de esta forma con el embrión del postulado realista, creyendo identificarlo, infructuosamente, una y otra vez. Galdós nos brinda la identidad del tipo en la frase que cierra el artículo «demos fin a este artículo, que debería haberse titulado El Vago».

Queremos terminar el apartado sobre técnicas o recursos literarios haciendo referencia al método empleado por un número considerable de colaboradores de la colección. Nos referimos a aquel en el que el autor, después de realizar una somera descripción generalizada del tipo en cuestión, lo clasifica en distintas modalidades, como si se tratara de una mera clasificación zoológica, donde cada especie presenta distintas variedades ${ }^{63}$. Estos costumbristas, en su intento de dar cuenta del tipo íntegramente, no se conforman con la escueta descripción del mismo, sino que intentan abarcar todas sus posibilidades, introduciendo pequeñas variantes como, por ejemplo, la del lugar o institución para la que trabajan. Este sería el caso de El maestro de escuela, artículo en el que se contraponen un maestro perteneciente a la Escuela Libre de Instrucción Primaria y otro, representante de la escuela municipal; o el titulado El pianista, en el que el autor clasifica al tipo según ejerza su oficio en una sala de conciertos, en un salón, en un café o en una tertulia - pianista de afición.

63 Vid. los artículos siguientes: El zarzuelero, El casero, El maestro de escuela, El petardista, El pianista, La parroquiana de café, El estudiante de medicina, El catalán, El del orden público, El... del comercio, El editor, Los pobres, El abogado, El revistero y El sastre. 
Todos estos artículos presentan ese carácter pedagógico-científico como tributo a la moda, importada por Balzac, de las fisiologías ${ }^{64}$. Su inclusión no representa ninguna originalidad propia de la colección. Ya en Larra encontramos artículos como El calavera donde se recurre a una clasificación que atiende a especies y castas, amén de recurrir a la fauna y flora - calavera doméstico, calavera-silvestre, calavera-langosta, calavera-mosca, calavera-tramposo, calavera-cura, viejo calavera y mujer calavera- - Sin embargo, en Larra no parece ser sólo un tributo a la influencia francesa sino que, como afirma el profesor Varela, se trata de un recurso satírico, "el de la perspectiva naturalista, que consiste, como dice su nombre, en la observación, descripción y clasificación seudocientífica de un tipo social o político» ${ }^{65}$, mientras que en nuestra colección, las referencias a la adscripción de las funciones del tipo al mundo de la zoología o de la botánica brillan por su ausencia.

Un aspecto que llama poderosamente la atención al estudiar la colección es la enorme atracción que sus colaboradores sintieron por los distintos usos del habla. Los españoles de ogaño se nos presenta como un rico mosaico o conglomerado donde anglicismos, galicismos e italianismos se mezclan con jergas y vulgarismos que intentan reflejar el estado y variedad del lenguaje de la época. Los ejemplos son numerosos y escasos los artículos en los que no aparece algún registro idiomático utilizado para definir y matizar al tipo descrito.

Los préstamos y variedades idiomáticas los encontramos ya a través del propio autor, cuando se sirve de ellos para describir al tipo y sus circunstancias, o bien cuando éste introduce un diálogo entre distintos personajes, diálogo que intentará reflejar la realidad del lenguaje utilizado en aquellos momentos. Estos diálogos generalmente recogen el habla vulgar o de germanía de distintos grupos sociales presentes en la colección, estando en perfecta

th Vid. a este respecto J. F. Montesinos, op. cit., pp. 95-106.

65 J. L. Varela, Larra y España, Madrid, Espasa Calpe, 1983, p. 107. 
adecuación con la condición social del personaje o personajes ${ }^{66}$. El lenguaje así utilizado se convierte en un auténtico complemento de la acción. Por ello, si la acción transcurre en los arrabales de la ciudad, el diálogo entre las vendedoras ambulantes y un agente del orden afluye con toda espontaneidad:

-Arriba, arriba, les dice el municipal; vamos pronto.

-Allá va; siñor, allá va, responde una de ellas. Vamos, Tomasa, date prisa, y tú, Manuela, que su señoría se aimpacienta. Miá tú y que pa esto hayamos hecho la rivolución, pa que no le permitan a una ganar honraamente una peseta.

- Pronto, andando, y chillar menos, repite el policía tropezando con el pie en la cesta de Tomasa, que sofocada y poniéndose en jarras grita a voz en cuello:

-Misté que a mí no me trompieza naide, ¿está V.? Y quien se mete con mi probesa se mete conmigo, y que no lo sepa mi Roque, porque le va a poner el cuerpo más morao que los vivos de su lebosa.

- Vamos, Tomasa, no tasofoques, y deja eso, que hay que tener más pacencia y más cachaza pa sufrir estas... pero ya vendrá el petrolio y... irábanos! ${ }^{67}$.

\section{Los vulgarismos son frecuentes cuando el autor debe dibujar tipos populares o las clases más bajas de la sociedad. Como sabe-}

66 La utilización del vulgarismo o del lenguaje de germanía es una práctica extendida entre los costumbristas románticos, como sería el caso de Estébanez Calderón o Mesonero Romanos. Salvo Larra, que en contadas ocasiones lo utiliza y casi siempre para corregir los defectos de dicción de los actores, el resto de los escritores los emplean para dar una mayor realidad al cuadro. Incluso algunos de ellos juegan con el vulgarismo para provocar la sonrisa del lector como en el caso de El Solitario en su artículo El asombro de los andaluces o Manolito Gázquez, perteneciente a las Escenas Andaluzas.

Esta modalidad aparece en la novela realista-naturalista. Recuérdense los casos de Galdós -Fortunata y Jacinta, Nazarín, Misericordia...-, Alarcón - El Niño de la Bola -, E. Pardo Bazán -Los pazos de Ulloa, La Madre Naturaleza, La tribuna-, Blasco Ibáñez - Cuentos valencianos, Cañas y barro, La barraca, Entre naranjos-. Incluso la crítica ha censurado en más de una ocasión a diferentes autores por no saber adecuar perfectamente la condición social del personaje con el uso de la lengua, como ocurriera con las novelas Pepita Jiménez o Juanita la Larga de Valera; así lo corroboran Montesinos o el mismo Baquero Goyanes.

Esta modalidad también se da en otros géneros literarios - sainetes y teatro costumbrista a lo Bretón de los Herreros-, pero tal vez sea más insistente en el cuento, artículo y novela. No olvidemos que el cuento escrito en verso, como El Diablo Mundo de Espronceda, ofrece un auténtico ejemplo de la utilización de este recurso. Recuérdense los consejos del tío Lucas a Adán y los diálogos protagonizados por Salada. 
mos, uno de los ingredientes básicos del lenguaje popular es el vulgarismo aunque los límites entre uno y otro sean difíciles de precisar ${ }^{68}$. En los párrafos en que aparecen diálogos entre tipos populares e incultos se aprecian todo tipo de asimilaciones, vacilaciones en las vocales átonas, alteraciones en los diptongos, metátesis, distorsiones morfológicas e, incluso, distorsiones sintácticas.

Intimamente relacionados con los vulgarismos surgen los gitanismos ${ }^{69}$ y términos correspondientes a un argot determinado: ambos aparecen entrecruzados y en numerosas ocasiones sus términos se suelen confundir. Expresiones como «tomar la embocadura», «tiene monos en la cara», «le va a arder el pelo a cualquiera», «pedir limosna por boca de ganso», «echa el pego», «las amarra y levanta muertos», «tomador del dos»..., o palabras como «saladero», «timba», «mengues», etc., las encontramos en el artículo El guripa, de A. Ruigómez e Ibarbia, en el que su autor pretende mostrar el uso habitual de estos registros en ciertos sectores sociales, ratificando así la opinión vertida en el párrafo que encabeza el artículo:

Ignoro qué razón pueda haber para que los escritores hablemos en caló; dicen que es moda, y siendo así, ya me libraría yo muy bien de contrariarla, tan sólo por no encontrar cosa que la justifique ${ }^{70}$.

El habla del hampa deja su huella en todos los lenguajes populares y también está presente en la colección estudiada. Algunas voces de esta procedencia alcanzan cierta extensión en el uso

68 Manuel Seco al referirse a los vulgarismos en su obra Arniches y el habla de Madrid, Madrid, Alfaguara, 1970, p. 143, realiza la siguiente precisión: «Lo vulgar es, con respecto a lo popular, sólo un componente caracterizador por la connotación inculta que el habitante medio descubre inmediatamente en la expresión de este tipo. El vulgarismo, pues, a diferencias del gitanismo o del argot, no representa un nivel social, sino un nivel cultural».

69 El gitanismo es otro de los ingredientes más frecuentemente utilizado en el habla popular madrileña. M. Seco en $o p$. cit., p. 130, afirma que «el influ jo cultural de lo gitano andaluz, atestiguado literariamente desde los tiempos de Cadalso y Jovellanos, abarca todo el siglo XIX y penetra aúiı vigoroso en el XX. La época de auge tal vez sea la de la Restauración».

70) El guripa, tomo I, p. 183. 
popular, perdiendo su dependencia con el mundo de la delincuencia; sin embargo, otras figurarán en estos textos solamente en boca de sus legítimos usuarios, funcionando precisamente como marcas caracterizadoras de los mismos. Esto último es lo que sucede, por ejemplo, con el diálogo sostenido por pequeños maleantes en El vendedor de periódicos. Por otro lado aparecen jergas propias de determinadas actividades, como la utilizada para describir la mala fortuna en el juego de la ruleta del tipo protagonista de El sietemesino. O como la relación de términos bursátiles que A. Ruigómez nos brinda al describir al protagonista de $E l$ banquero.

El uso del habla regional como marca caracterizadora del tipo descrito también se encuentra presente en Los españoles de ogaño y, aunque es el andaluz, plagado de gitanismos y vulgarismos, el de mayor representación, aparecen también algunos destellos propios del gallego. El empleo de lenguas y dialectos peninsulares va a encontrar propugnadores en estos costumbristas, atentos al detalle, que se limitan en un principio a la simple transcripción de las formas fonéticas más aparentes. Mesonero Romanos fue el primero que inició su empleo en artículos como La posada, donde diversos tipos dan motivo a un despliegue de variedades regionales - gallego, andaluz, catalán y valenciano-; en el artículo El Romanticismo y los románticos transcribe galleguismos castellanizados; en La calle de Toledo, Mesonero imita el habla andaluza. A partir de este autor muchos costumbristas van a seguir sus pasos llegando incluso a superarlo en este aspecto, como sucede con Antonio Flores, costumbrista que refleja el habla popular madrileña con todo acierto. Del habla andaluza resaltamos en nuestra colección el empleo que de ella hace $\mathrm{C}$. Moreno López en su artículo El torero de afición, en el que aparece Castañitas, torero de origen andaluz:

-Castañitas, creo que tu podrías encargarte de buscarnos los trastos y...

-Zeñorito Téllez, zi ustez quieren, yo corro con too ezo, y respondo de que en la plaza naica hará farta. ¿Estamos? Yo zoi asina, mu 
echao pa lante, y amigo de miz amigos, ¡chipé! y yo estaré ayí pa que no haiga un desavío. ¿Estamos? ${ }^{71}$.

La mayor presencia del andaluz en la colección está plenamente justificada si tenemos en cuenta la atención que desde finales del siglo XVIII se venía prestando en la capital a todo lo proveniente de las tierras meridionales. Desde los trajes, cantes, bailes..., hasta el lenguaje caló, están de moda en la capital del reino durante el Romanticismo y son precisamente las clases populares las que acogen con mayor profusión sus innovaciones. Esta influencia se debió sin duda a factores tan diversos como el interés despertado en los extrajeros por la España pintoresca, que tan nítidamente está representada por Andalucía, o factores políticos, como el hecho de la invasión francesa, que recluyó al gobierno en Cádiz, y al sentimiento de exaltación de lo nacional que se desarrolló al terminar la guerra, factores que contribuyeron a que el andalucismo de las costumbres se acentuase sensiblemente ${ }^{72}$.

Sólo encontramos una nueva lengua reflejada en la colección: el gallego, única lengua que intenta competir, sin conseguirlo, con las reiteradas y amplias representaciones del andaluz. Los tipos gallegos únicamente van a ser caracterizados por el empleo aislado de determinadas frases o expresiones en su lengua nativa, como sucede, por ejemplo, en El cochero de alquiler de E. Palacio, o por rasgos puramente convencionales como puede ser caracterizar al tipo gallego por el uso indiscriminado de palabras terminadas en -u, como se aprecia en el párrafo que a continuación reproducimos:

-Quien debe deciochu y paja decinueve...

- ¡Paja!, paja debe tú comer, maruso, exclamó Dominga, soltando la risa y pasando de largo.

71 El torero de afición, tomo 1, p. 265.

72 Testimonios de esta influencia andaluza en la capital del reino se encuentran abundantemente en Los españoles pintados por símismos. Vid. por ejemplo, los artículos El alcalde de montería y La maja, de Fermin Caballero y Manuel de Santa Ana, respectivamente. 
- iAh rapaza; cundenada! Mal demu, si cuando lleve el cincu nun te doy un apretonciñu ${ }^{73}$.

La utilización de términos extranjeros es también muy abundante en la colección, hasta el punto de que lo difícil es encontrar artículos en los que no hallemos una muestra de ellos. Estos términos procedentes de lenguas distintas al castellano se imprimen en cursiva, como si el autor quisiera resaltar su uso. El mayor porcentaje de palabras extranjeras empleadas en los artículos recaerá, lógicamente, sobre el francés, siendo el italiano y el inglés las otras dos lenguas presentes en la obra.

La inclusión de términos franceses está motivada por la indudable influencia que el país vecino venía ejerciendo en la España del siglo XIX. La utilización de giros, frases y palabras francesas por parte de las clases sociales más altas aparece atestiguada ya en Los españoles pintados por sí mismos. Sin embargo, en nuestra colección, no sólo la burguesía y la aristocracia madrileña recogerán galicismos como sinónimo de exquisitez y buen gusto, sino que aparecerán también en boca de la pequeña burguesía comercial o en la del funcionario. Su uso, pues, se nos presenta más generalizado que en la colección de 1843, y esta generalización va a ser criticada y ridiculizada por los costumbristas, que irónicamente afirman, por ejemplo:

Las burras de leche se disponen ya a recogerse y Madrid duerme; Madrid elegante, Madrid comm'il faut: hablaremos a la moda ${ }^{74}$.

Yo me admiro - ahora me ha dado por las admiraciones-, de mi valor heroico. Voy a ponerme en contradicción con un refrán castellano, que hasta hoy no había negado nadie.

No hay que mentar la soga en casa del ahorcado.

$Y$ esto de desmentir un evangelio, aunque sea chico, me parece grave, trop fort, para que ustedes me entiendan ${ }^{75}$.

73 La niñera, tomo II, p. 61.

74 El gorrista, tomo II, p. 68.

75 El editor, tomo I, p. 385. 
Pero no sólo van a contentarse con apreciaciones irónicas como las señaladas, sino que algunos autores reaccionan con auténtica fobia, proyectando en el lector una figura altamente censurable o despreciable. Un ejemplo de lo que acabamos de afirmar lo encontramos en el artículo de J. Soriano de Castro El empleado, en el que la figura del afrancesado aparece duramente ridiculizada:

- iCarlos! prorrumpe nuestro antiguo conocido.

- ¿Lois!, gruñe con acento transpirenaico el nuevo personaje.

- ¿Qué milagro es éste? ¿Tú por aquí?

-iOh!, no estar milagro como tú te supones, continúa el galo atusándose el pelo; soy venido por ver el jefe de un apartamente, en servicio de mi affaire.

- ¿Negocio tuyo?, interroga Luisito que sabe decir bon soir, bailar wals corrido, y recostarse en la fachada de casa de Lhardy las tardes en que llueve.

-Negosia oficial, mon cher ami; mí estar empleado despuis long temps $^{76}$.

Los italianismos, al igual que los galicismos, son utilizados por tipos que, perteneciendo a la burguesía, pretenden imitar el modo de vida y reuniones sociales características de la aristocracia madrileña. Los italianos sin embargo sólo hacen referencia, en la mayoría de los casos, a términos del lenguaje musical ${ }^{77}$, aunque en alguna ocasión se introduzcan expresiones del tipo "Ecco il problema» ${ }^{78}$ en medio de una descripción. Las palabras inglesas son escasas, encontrándolas sólo en dos artículos de la colección: El orador de club y La mamá de teatro.

$\mathrm{Si}$ intentamos reflejar escuetamente la intención que parece guiar a estos costumbristas, observamos que el propósito ético-

76 El empleado, tomo I, pp. 246 y 247 . La denuncia y sátira protagonizada por los afrancesados tiene en nuestra historia literaria numerosos ejemplos. Podemos decir que a partir del siglo XVIII, con la publicación de las Cartas Marruecas, se generaliza esta costumbre, siendo materia obligada tanto para los costumbristas románticos como para los pertenecientes a esta época.

77 Vid. por ejemplo, el artículo El pianista, tomo I, pp. 131-145.

78 El cómico casero, tomo II, p. 114. 
docente clásico del costumbrismo se encuentra latente en nuestra colección. Son numerosos los artículos donde se engarzan perfectamente lo descriptivo con la intención moralizante. Dicha tonalidad o bien está implícita en la presentación de la historia, o aparece al comienzo o al final del cuadro en breves digresiones. Mesonero Romanos nos habla, en más de una ocasión, de lo que debe ser el costumbrismo, indicando que no sólo debe considerarse como un reflejo histórico del momento vivido, sino que también debe concebirse «como una lección moral, más o menos severa, que lleva envuelto el noble objeto de mejorar la condición y las inclinaciones humanas ${ }^{79}$. La consabida lección moral llevará implícita la sátira y, por ende, el defecto o vicio al uso protagonizará, en no pocas ocasiones, las páginas de esta colección. De ahí que el escenario costumbrista con sus multiformes tipos sea el envés de las buenas costumbres, desfilando una serie ininterrumpida de defectos que aquejan a esta sociedad.

De Los españoles de ogaño se desprenden sucesivas notas y aspectos negativos de la vida española de aquellos años. Parece como si sus colaboradores se hubiesen puesto de acuerdo para producir en el lector sensaciones de desencanto y amargura. A través de los tipos que presentan entrevemos todo un panorama de pesimismo moral, social y político y, frente a los artículos donde se aprecia el tono dulzón y benevolente de Mesonero Romanos, se alza, en la mayoría de las ocasiones, la voz de unos costumbristas que denuncian, a la manera de Larra, la mediocridad del momento. Larra parece actuar como mentor ideológico de estos costumbristas que ven con pesimismo el futuro de España, al ofrecer una sociedad donde la envidia, la ignorancia, el engaño, la falsa apariencia..., lo inundan todo. No se observa en los artículos ninguna esperanza en el porvenir y al contrario de los costumbristas anteriores, ya ni siquiera el consuelo de afirmar el tópico de que todo tiempo pasado fue mejor; es decir, no encuentran un espejo donde asomarse, ni un modelo hacia donde ir. Creemos que lo que se refleja en la colección no es sólo la si-

79 Vid. su artículo Panorama Matritense. 
tuación socio-política de ese momento, sino el lastre económico y político de la centuria y el desconcierto provocado por la revolución del 68. Los rápidos vaivenes políticos de la época parecen haber acabado con toda perspectiva de mejora para unos hombres que no son capaces de sacar a España del estancamiento social, moral y político que se ha ido produciendo con el paso de los años. 